\title{
KARL-OTTO APEL Y EL PUNTO DE VISTA ÉTICO-DISCURSIVO SOBRE LA TOLERANCIA AFIRMATIVA
}

\author{
Mauricio Correa-Casanova \\ Pontificia Universidad Católica de Valparaíso \\ maucorca@yahoo.com
}

\begin{abstract}
Resumen
En este artículo, el autor desarrolla el problema de la tolerancia en una sociedad multicultural según el planteamiento de Karl-Otto Apel y el punto de vista de la ética del discurso. En este sentido, parte explicando que el problema actual de la tolerancia consiste en el desafío de abrir un espacio a las diferentes formas de vida socio-cultural. Así, expone las contradicciones de la versión de tolerancia negativa en el liberalismo y las insuficiencias de la crítica comunitarista. Luego, se presenta la propuesta de fundamentación ético-discursiva de lo que el filósofo alemán llama como 'tolerancia afirmativa'. Se concluye con algunas consideraciones valorativas: primero, para cuestionar la necesidad de la tolerancia afirmativa en un régimen constitucional, y segundo, para postular que la fundamentación ético-discursiva de la tolerancia encuentra su derivación más coherente en la categoría del respeto.
\end{abstract}

Palabras clave: ética del discurso, formas de vida socio-cultural, tolerancia negativa, tolerancia afirmativa, respeto, liberalismo, comunitarismo.

\section{Abstract}

In this article the author develops the problem of tolerance in a multicultural society according to Karl-Otto Apel's position and the point of view of the ethics of discourse. The author explains that the challenge of opening a space to different forms of socio-cultural life is the current problem of tolerance. This way, he exposes the contradictions of the negative tolerance in liberalism and the communitarian critical insufficiencies. Therefore, he presents the proposal of ethical-discursive basis about what the German philosopher has called 'affirmative tolerance'. This study concludes with some value considerations which are meant to question the necessity of affirmative tolerance in a constitutional regime, in first place, and to postulate, in second place, that the ethical-discursive basis of tolerance finds a more coherent derivation in the category of respect.

KeYwords: discourse ethics, forms of socio-cultural life, negative tolerance, affirmative tolerance, respect, liberalism, communitarianism. 
$\overline{\mathrm{RA}}$ Como es sabido, junto con Habermas, Apel representa en el mundo de la filosofía moral y política contemporánea uno de los gestores y defensores de la bien conocida "ética del discurso" (Apel 1985, 1986, 1995; Habermas 1998a, 1998b, 2000). En este sentido, como es obvio, su reflexión en torno a la tolerancia se desarrolla principalmente desde un punto de vista ético, tal como lo destaca en el único artículo en el que se ha pronunciado públicamente sobre el tema, el cual lleva por título: "Plurality of the Good? The Problem of Affirmative Tolerance in a Multicultural Society from an Ethical Point of View" (Apel 1997a).

En este trabajo, Apel comienza distinguiendo en la historia de occidente tres casos paradigmáticos de tolerancia que van configurando sucesivamente la libertad religiosa, la libertad de opinión y de expresión y, por último, en nuestros días, la que pone de manifiesto la necesidad de un espacio libre para la "auto-manifestación de las diferentes formas de vida sociocultural" (self-display of different sociocultural forms of life) (Apel 1997a, p. 199). Para nuestro autor, el primero de estos casos paradigmáticos de tolerancia se establece como consecuencia de la Ilustración y de la separación entre la Iglesia y el Estado; el segundo, con relativa independencia del primero, surge como una reacción no solo contra la Iglesia, sino también contra los excesos del Estado secular (por ejemplo, contra el nacionalismo u otras ideologías políticas totalitarias); el tercero, finalmente, resulta ser un caso paradigmático emergente, aún no configurado por completo, y que, en consecuencia, orienta la reflexión filosófica de nuestros días.

A este tenor, habría que especificar que Apel centra su reflexión y discusión filosófica principalmente en torno al tercer caso paradigmático de tolerancia que hemos mencionado, el cual se presenta con un carácter más comprehensivo y, a la vez, complejo. Comprehensivo, porque pretende abarcar las diferentes formas de vida sociocultural y ya no tan solo garantizar la libertad de conciencia y de expresión. Complejo, porque es ambiguo a la hora de establecer quién ha de ejercer la tolerancia (por ejemplo, si alguna comunidad particular a través del monopolio de la fuerza del Estado) y contra quién ha de ser garantizada (es decir, quién puede representar en las actuales condiciones históricas una amenaza para la automanifestación libre de las distintas formas de vida sociocultural).

Pues bien, en este artículo examinaremos las principales ideas expuestas por Apel sobre este tópico, desarrollando los siguientes temas: en primer lugar, comenzaremos con el planteamiento del problema de la tolerancia en la ética del discurso y la distinción de Apel entre dos formas de tolerancia; en segundo lugar, consideramos el planteamiento crítico de la tolerancia negativa desde la perspectiva del comunitarismo, así como las contradicciones de su propio punto de vista según Apel; en tercer lugar, nos detenemos en la consideración de las insuficiencias de la tolerancia negativa en un régimen constitucional liberal desde un punto de vista ético-discursivo; en cuarto lugar, tratamos sobre la fundamentación ético-discursiva de la tolerancia afirmativa; por último, ofrecemos algunas consideraciones valorativas sobre la versión apeliana 
de la tolerancia afirmativa, primero para cuestionar su necesidad, y segundo, para postular que la fundamentación ético-discursiva de la tolerancia encuentra su derivación más coherente en la categoría del respeto (activo), tal como ha postulado Adela Cortina.

\section{Planteamiento del problema de la tolerancia en la versión de la ética del discurso}

A la ética del discurso se han dirigido un buen número de críticas provenientes no solo de sus adversarios - tales como los racionalistas críticos, emotivistas, contextualistas, hegelianos y, como no podía ser menos, de los postmodernos-, sino también del propio círculo de adeptos (Cortina 1995a, también de la misma autora 1989, 1992, 1995b, 1995c; Blanco, Pérez y Sáez 1994, Dussel 1998, Muguerza 1991). No obstante, y sin adentrarnos en tan apasionante debate, quisiera comenzar más bien con el planteamiento mismo del problema de la tolerancia en la versión de la ética del discurso.

Como ya hemos anticipado, Apel distingue entre tres casos paradigmáticos de tolerancia que han encontrado su concreción histórica definitiva en el reconocimiento moral, político y jurídico de los derechos subjetivos por parte del Estado de derecho, esto es, la libertad religiosa, de opinión y de expresión. El caso paradigmático más actual, y que ocupa el centro de atención, sería aquel que exige además el reconocimiento de la automanifestación libre de las variadas formas de vida socicultural que se dan en la sociedad multicultural.

En este contexto, Apel no restringe ni agota su reflexión en las garantías político-jurídicas del Estado de derecho típicamente liberal, sino que, sobre la base de dichas garantías, más bien las enfoca desde la perspectiva que supone una exigencia más profunda de reconomiento, si se quiere promocional, afirmativo o positivo como las llama él mismo, que potencie las diferentes formas del ethos sociocultural y que vaya más allá de la simple garantía del reconocimiento de los derechos subjetivos y los límites impuestos por el derecho. En este sentido, como abiertamente reconoce Apel, su esfuerzo por dar una respuesta al desafío de la tolerancia en la sociedad multicultural es estrictamente filosófico, más concretamente aun, intenta proporcionar una solución adecuada desde "el punto de vista de la ética filosófica en un sentido amplio" (Apel 1997a, p. 202).

Así pues, en esta línea de reflexión ética sobre el tercer caso paradigmático de tolerancia, Apel comienza por distinguir entre dos modelos de tolerancia, uno que denomina como "tolerancia negativa" (negative toleration); y el otro, como "tolerancia afirmativa" (affirmative toleration), que corresponde al modelo formulado y defendido por él mismo (Apel 1997a, p. 200). El primer modelo coincide con la versión proporcionada por el liberalismo clásico y estaría basado en la indiferencia hacia las distintas formas particulares del ethos comunitario; en cambio, el segundo, se basa en la apreciación de que las tradiciones de valor profundas y diversas son fuentes que 
pueden enriquecer la cultura humana en general y el compromiso social de los individuos.

A la luz de la distinción precedente, la tesis de fondo que viene a sostener Apel consiste en afirmar que es necesario introducir una noción diferente de tolerancia a la propuesta por el liberalismo, ya que la tolerancia negativa - esto es, las garantías constitucionales del derecho fundamental a la igualdad- es insuficiente dentro del contexto de una sociedad multicultural. En este sentido, no basta una noción puramente legal para satisfacer las exigencias de las distintas formas de vida sociocultural, sino que además habría que apoyarla en un punto de vista ético. En una sociedad multicultural, por lo tanto, no basta con que todos se encuentren en la obligación de abstenerse de interferir con las tradiciones o las formas de vida de los demás, pues esa práctica de la tolerancia es insuficiente para proporcionar cohesión social y lealtad política entre los ciudadanos. Al decir de Apel: "sólo sobre presupuestos hobbesianos, a saber, el autointerés estratégicamente calculado y las sanciones legales, uno no puede siquiera ofrecer una base moral para la justicia como igualdad de derechos" (Apel 1997a, pp. 200-201).

En virtud de los límites de la tolerancia negativa basada sobre un cierto tipo de liberalismo orientado económica y jurídicamente, Apel persigue demostrar en contrapartida que el punto de vista de la ética del discurso proporciona la perspectiva normativa más básica para apoyar una noción de tolerancia afirmativa, y esto por el siguiente motivo: porque "nosotros, es decir, los miembros virtuales de la comunidad discursiva, somos responsables - o, más precisamente, co-responsables- por los efectos y efectos secundarios de nuestras acciones y actividades colectivas, y esto significa, por la formación y transformación de todas las instituciones o, a escala más amplia, de todos los subsistemas funcionales de la sociedad, tales como, por ejemplo, los de la ley y el poder político" (Apel 1997a, p. 202).

En cierto modo, entonces, el modelo de tolerancia afirmativa propuesto por Apel se ubicaría cercanamente al tipo de ethos republicano de solidaridad que pretende proporcionar una base moral para apreciar las distintas tradiciones de valor, así como también al proyecto multicultural que, reconociendo el valor de las diferencias, desea abrirles un espacio social. Sin embargo, como veremos en su momento, el tipo de solidaridad y apertura hacia las distintas formas de vida socio-cultural propuesto por Apel mantiene sus propias peculiaridades en cuanto no se origina a partir de una valoración fuerte del ethos comunitario particular y contingente, sino en las exigencias del a priori de la comunidad de comunicación dada anticipadamente (en sentido trascendental) a los diálogos entre las comunidades reales de comunicación. Como sin reconocimiento recíproco no es posible la solidaridad entre personas auto-responsables y co-responsables con igualdad de derechos, a juicio de Apel, la tolerancia afirmativa es una condición básica de la justicia para la convivencia humana en libertad y, en tanto condición de la justicia, una exigencia ética que a nadie le puede ser negada. Pero, ¿es posible fundar éticamente una noción de tolerancia afirmativa? 


\section{Las contradicciones de la tolerancia en la versión del comunitarismo}

Como hemos dicho, la reflexión filosófica apeliana se encuentra fijada por las condiciones de posibilidad del principio de tolerancia en el contexto de las sociedades multiculturales en las que se pone de manifiesto una variedad de formas de vida sociocultural. En este sentido, para Apel la complejidad respecto al tema de la tolerancia en las condiciones de la sociedad multicultural concierne a quién ha de ejercer la tolerancia y contra quién ha de ser garantizada. Así, y con el fin de responder a ambas cuestiones, nuestro autor comienza considerando el problema en las versiones del comunitarismo y del liberalismo.

Una primera aproximación al problema de la tolerancia se desprende del punto de vista del comunitarismo anglo-americano que se contrapone al liberalismo. En efecto, la propuesta del principio de tolerancia persigue para cierto tipo de comunitarismo ético defender a las comunidades socioculturales y las tradiciones de valores particulares en contra del Estado liberal moderno, el cual solo se preocupa por los intereses y derechos individuales, siendo por ello completamente indiferente hacia las distintas formas de vida socio-cultural (Apel 1997a, p. 200). Así, el Estado liberal basado en el individualismo sería la causa última, según las distintas versiones del comunitarismo, de la fuerte pérdida de todos los valores y las virtudes sociales de lealtad y solidaridad en las sociedades capitalistas modernas compuestas de egoístas estratégicos que solo se preocupan por un Estado que proteja el cuidado del contrato social a través de sanciones jurídicas.

El planteamiento general del punto de vista comunitarista contra el Estado liberal, sin embargo, a juicio de Apel, adolece de graves y peligrosos defectos que pueden representar más bien un poderoso obstáculo para la realización misma del principio de tolerancia. En efecto, en la medida en que ciertas versiones del proyecto comunitarista pretenden refundar el ethos republicano sobre las valoraciones fuertes de una tradición etnocultural, es decir, de una eticidad substancial en sentido hegeliano, el camino para la auto-manifestación libre de las formas de vida sociocultural puede presentarse como un callejón sin salida. Pues, de forma inevitable los comunitaristas se ven confrontados a la pregunta de cómo tolerar entonces las diferentes manifestaciones de formas de vida socioculturales, garantizando, por ejemplo, la automanifestación libre de las opciones morales de vida individuales frente a las reivindicaciones dogmáticas de la lealtad colectiva (Papacchini 1996, Crisp 1992, Thiebaut 1991). En este sentido, no todas las valoraciones fuertes del ethos comunitario poseen una exigencia válida de cumplimiento universal extensible a todas las formas de vida socio-cultural.

La situación empeora aún más si se tiene en cuenta que muchos de los defensores del comunitarismo se empeñan en negar explícitamente cualquier posibilidad de un fundamento autónomo y racional de las normas de ética válidas universalmente (Siurana 2003). A juicio de Apel, este posicionamiento ético no solo prejuzga la estructura lógica del comunitarismo, sino que además hace imposible una base normativa aceptable y válida para la tolerancia afirmativa de las distintas formas del ethos comunitario dado de forma contingente. 
Un autor como Walzer, por ejemplo, niega la posibilidad de cualquier fundamento semejante bajo premisas contextualistas y empiricistas. En su caso, basta con decir aquí que para la explicación de todas las normas fundamentales de validez universal es necesario recurrir a una especie de abstracción sobre la base de las mismas tradiciones comprehensivas del ethos. En el seno de dichas tradiciones densas y particulares se encontraría lo que Walzer llama un minimalismo moral, el cual expresaría un tipo de universalismo tenue o débil que nos permitiría relacionarnos con pueblos de diferentes culturas en los momentos de crisis política y moral (por ejemplo, ante la tiranía que sufren algunos pueblos) (Walzer 1996). Frente a esta propuesta no filosófica, sino enraizada en la realidad histórico-cultural contingente, sin embargo, Apel sostiene que Walzer confunde entre la dimensión genética de los valores, cuyo origen debe buscarse evidentemente en el contexto de alguna tradición comunitaria de desarrollo histórico; y la dimensión justificatoria o de validez de las normas éticas, la cual debe superar el mecanismo autorreferente de las propias tradiciones del ethos situadas de forma históricamente contingente.

Así pues, Apel afirma que Walzer en general lleva razón al solventar el problema de la moralidad en el ámbito internacional (o ética universal) mediante el recurso a experiencias en las que se comparten de forma intercultural un mínimo de valores comunes. Incluso este punto de vista puede considerarse como una contribución importante para ponderar todas las demás versiones del comunitarismo. Sin embargo, este primer aspecto desarrollado desde premisas empiricistas y comunitaristas no puede ser considerado como suficiente con el fin de satisfacer la exigencia de justificación de orden filosófico-moral al desafío de justificar la validez universal de las normas, así como tampoco para ofrecer una base normativa aceptable para la tolerancia de las diferentes formas de vida sociocultural.

Dicho brevemente, la base empiricista y contextualista para la tolerancia en la sociedad multicultural solo puede justificar la coexistencia entre las distintas formas del ethos comunitario en virtud de la dominación de una forma particular del ethos sobre las demás según un determinado equilibrio de poder (una alternativa que contradice la crítica de etnocentrismo que el comunitarismo lanza a la solución liberal). Incluso, y lo que no es de poca monta, la falta de una justificación de validez auténticamente universal para las normas éticas puede conducir en la era de la globalización al eventual contrasentido de legitimar, por ejemplo, formas de tolerancia que alcanzan cotas insuperables frente al caso de la violación de los derechos humanos. Por cierto que con esta crítica, Apel no quiere decir que Walzer justifique desde sus premisas contextualistas, quizás de modo indirecto, tales violaciones, sino más bien que no cuenta con una base normativa ética de validez universal que sea capaz de solventar de forma racional e intersubjetivamente válida su crítica y condena. En la base de sus argumentaciones, Walzer desconoce el hecho según el cual desde la modernidad se entiende con Kant que la razón práctica se dirige a priori al principio de universalización de la justicia que trasciende ya siempre cada autointerés empíricamente dado sobre la base de un ethos particularmente determinado.

Otro autor, como Taylor, tampoco escapa a esta crítica aun a pesar del recurso a lo que Apel denomina como "comunitarismo universalista" (aunque, ciertamente, 
no trascendental). Como es sabido, Taylor no parte de un modelo de comunidad particular, cerrada e históricamente contingente, sino de la historia del progreso de la cultura humana occidental considerada en su totalidad (Taylor 1999). Por esta vía se deriva en algo así como una síntesis posterior de tradiciones parciales de raigambre occidental que ha traído como consecuencia la democracia moderna, configurada por el liberalismo de Locke y por el republicanismo, en el sentido de Tocqueville. Desde esta perspectiva, a juicio de Apel, Taylor expondría un comunitarismo universalista, aunque no en el sentido de que lleve a cabo una diferenciación entre el principio universal y procedimental-comunitario de la justicia, por una parte, y las formas plurales y particulares de comunidad de vida buena, por la otra; sino en cuanto dicho universalismo estaría asentado específicamente en la idea de una síntesis substancialista en sentido hegeliano, esto es, que asume y trasciende (aufhebt) las pretensiones universales de libertad y justicia (y también de la religión cristiana).

A este tenor, sin embargo, Apel considera que el universalismo de Taylor no es suficiente para superar las contradicciones inherentes al comunitarismo. En efecto, vista desde la exigencia de tolerancia en el centro de las tradiciones opuestas del ethos comunitario, habría que preguntarse si a partir de la identidad del hombre moderno existe la disposición a hacer justicia también (o incluso) a las tradiciones culturales no-occidentales, esto es, a aquellas tradiciones que se escapan a la síntesis substancial de estilo hegeliano, y que, precisamente por eso, tienen que ser, en su pluralidad y diferencialidad, protegidas en contra del eurocentrismo (o sea, en contra de una política asimilacionista). En este sentido, en opinión de Apel, el comunitarismo universalista tayloriano no deja de ser un "universal concreto" (también en sentido hegeliano), con lo que el ethos particular y contingente resulta irrebasable (al menos en el sentido no trascendental del comunitarismo).

En palabras de Apel: "Cualquier sintesis ex-post desde el punto de vista del presente deja fuera de sí la mediación comunicativo-discursiva referida al futuro, es decir, todavía por realizar, del principio de la justicia, a través del acuerdo y la formación del consenso con el 'otro', por ejemplo, con las culturas no-integrables, no occidentales” (Apel 1994, pp. 24-25). Con esto quedan en evidencia los límites filosóficomorales de cualquier posible comunitarismo no trascendental que pretenda aglutinar en un solo momento (es decir, en el momento universalista de la moralidad en el sentido de Kant) el progreso de la eticidad substancial, ya que siempre (a la sombra de Hegel) será insuperable el universal concreto de una comunidad (o síntesis ex-post de comunidades) que existen de hecho aglutinadas en la facticidad de lo particular. Por este motivo, permanece aún sin solución satisfactoria la posibilidad de la tolerancia afirmativa frente a las formas de vida socio-cultural no occidentales.

Con todo, la perspectiva apeliana se distancia de los comunitaristas en general en cuanto no se basa directamente en el ethos de las comunidades particulares o de las tradiciones de valores que conforman la llamada sociedad multicultural. En este sentido, Apel propone lo que denomina como un "comunitarismo no-particularista del $a$ priori de la comunidad de comunicación” (Apel 1994, p. 22). Sin desdeñar lo que de positivo posee el comunitarismo, nuestro autor sostiene que la idea del a priori de la comunidad de comunicación expresa también a su modo una especie de comunitarismo 
que él denomina como trascendental y que estaría presente desde el inicio en la formulación de la ética del discurso (Apel 1994, p. 16). En sus propias palabras: "Se podría hablar de un comunitarismo trascendental o de una filosofía trascendental de la intersubjetividad, en el sentido de una reciprocidad estrictamente generalizada" (Apel 1994, p. 23).

Esto supone que todo ser dotado de competencia comunicativa está inserto al mismo tiempo en dos comunidades: una real, que sería la comunidad histórica de origen, contingente y en la que cada uno se socializa; y otra ideal o, mejor, trascendental, la cual se anticipa contrafácticamente en toda argumentación con sentido. De este modo, según Apel, la comunidad ideal ilimitada de comunicación debe ser anticipada como referencia a las condiciones ideales de discurso en cada discurso real en que se busca la solución argumentativa o la comprobación crítica de pretensiones de validez. Sin embargo, como la comunidad ideal de comunicación, en cuanto idea regulativa, no está realizada en el espacio y el tiempo, entonces no ha de pensarse en ella como un hecho dado empíricamente. Por esta razón, y siguiendo la línea de una ética post-weberiana de la responsabilidad, una praxis basada exclusivamente en la comunidad ideal sería irresponsable, pues nadie garantiza que obrando de ese modo los demás vayan a hacer lo mismo. De ahí que una exigencia moral imprescindible consista en conservar siempre la referencia a la comunidad real en la búsqueda de acuerdos dentro de las contingencias históricas del ethos empíricamente dado, ya que solo de ese modo se hace posible ir poniendo dialécticamente -o sea, en el horizonte pragmático-trascendental de toda argumentación- las condiciones para alcanzar algún día el cumplimiento de las reglas de la comunidad trascendental.

Para Apel, en este sentido, la tarea principal consiste en indicar las condiciones comunitarias de la identidad personal post-convencional del hombre moderno. Dicha identidad no puede estar fijada solo históricamente, sino que al menos también ha de estar determinada por la referencia esencial del sujeto de la razón práctica a la comunidad ideal de comunicación anticipada contrafácticamente. Cada hombre de buena voluntad, por tanto, ha de colaborar en la producción a largo plazo de las condiciones de aplicación de la ética del discurso. Lo cual quiere decir, en palabras de Apel, que "la realización de las condiciones de aplicación de la ética del discurso se convierte ahora en un telos, a cuya luz también las valoraciones referidas a la situación son posibles y necesarias" (Apel 1994, p. 32). Con ello la meta y sus correspondientes valoraciones se convierten en obligaciones teleológico-valorativas válidas universalmente a las que cada hombre debe corresponder (Siurana 2003, pp. 171-172).

De este modo, en la versión pragmático-trascendental de la ética del discurso apeliana, el camino de la reflexión filosófica sobre los presupuestos trascendentales de la argumentación representan el único modo posible para evitar la metafísica (o una doctrina comprehensiva de la metafísica) y con ello la dependencia cultural. En este sentido, no se trata, ciertamente, de un recurso a hechos empíricos ni tampoco, en modo alguno, a una investigación antropológica o sociológica (lo que, a juicio de Apel, parece ser extremadamente difícil de entender para la mayoría de nuestros contemporáneos), puesto que indaga los principios morales que nosotros -en orden a salvar la autoconciencia de la razón-debemos reconocer incluso si (o, según el caso, 
cuando) consideramos todas las formas del ethos empíricamente dadas solo como hechos convencionales de los cuales no pueden ser derivadas ni normas vinculantes ni compromisos morales (Apel 1997a, pp. 202-203).

No hay duda de que este camino, distante de las aproximaciones pragmáticas y empíricas que sustentan los acuerdos fácticos predominantes en la actualidad -piénsese, según Apel, en autores tales como Rawls o Walzer-, resulta a lo menos bastante novedoso para abordar el tema de la tolerancia. En efecto, para Apel la cuestión de fondo sobre la tolerancia afirmativa apunta a la posibilidad de proporcionar una fundamentación racional en base a unas exigencias éticas que puedan ser universalmente válidas, cuestión que desde su punto de vista aún se encuentra sin resolver en la medida en que la mera tolerancia negativa tras su aparente triunfalismo resulta ser una respuesta todavía insatisfactoria. Aun peor, en la medida en que se ha evadido el problema de una fundamentación de la ética con validez universal por medio del recurso pragmático-hermenéutico a las costumbres de una forma de vida dada como base contingente del consenso, la tolerancia afirmativa es imposible.

\section{Las insuficiencias de la tolerancia negativa en el liberalismo}

Ahora bien, si el comunitarismo resulta contradictorio al ofrecer una respuesta satisfactoria ante la posibilidad de una tolerancia afirmativa, tal parece que el modelo de tolerancia negativa ofrecido por el liberalismo en general -precisamente el modelo hacia el cual el comunitarismo lanza sus críticas-, posee ventajas que son a estas alturas irrenunciables. De hecho, la garantía de los derechos individuales por parte del Estado liberal y su principio de neutralidad representan en su conjunto los mayores beneficios obtenidos para la democracia moderna a partir de la política de la tolerancia religiosa gestada en los siglos XVI y XVII, tal como muestran los resultados de Locke o S. Mill. En este sentido, y tal como afirma Apel: "Durante la pasada centuria, todos los proyectos históricamente realizados de reemplazar el Estado liberal y su neutralidad hacia las tradiciones etno-religiosas por un Estado basado sobre fuertes tradiciones comunitarias de lealtad valórica sólo condujeron a la destrucción de la tolerancia hacia los derechos individuales y aquellos colectivos minoritarios [...]. Por lo tanto, parece que sólo el liberalismo y su neutralidad hacia las tradiciones de valores particulares puede proporcionar la posibilidad del tipo de tolerancia [negativa] que es la precondición para una sociedad multicultural" (Apel 1997a, p. 200).

En otras palabras, tal parece que solo la tolerancia negativa, en tanto expresión del derecho de todo individuo a no ser obstaculizado en el ejercicio de su libertad, es suficiente para garantizar a su vez la auto-manifestación de las distintas formas de vida que expresan las tradiciones de valor existentes en la sociedad multicultural. Sin embargo, y a pesar del aparente halo triunfalista del liberalismo en general, quizás sea pertinente examinar con cuidado si la pura garantía de los derechos individuales ofrece una base moral pública aceptable para la justicia entendida como la igualdad de derechos de las distintas formas del ethos sociocultural. Precisamente, en lo que sigue nos detendremos en este aspecto, considerando especialmente la posición de Rawls. 
Para comenzar, Apel considera que el liberalismo en general, en tanto visión filosófico-ideológica, resulta ser la expresión de la complementariedad existente entre el objetivismo no valorativo de la ciencia, por una parte, y el subjetivismo existencial de los actos religiosos de fe y de las decisiones éticas, por la otra. Esta complementariedad se traduce en la separación liberal entre los ámbitos de la vida pública y la vida privada, la cual se ha configurado en conexión, primero, con la separación entre la Iglesia y el Estado, y luego, en nuestros días, con la separación entre moral y Derecho. En este sentido, Apel nos dirá: "el liberalismo occidental ha reducido cada vez más a la esfera de las decisiones privadas de conciencia, primero la obligatoriedad de la fe religiosa y, a continuación, el carácter obligatorio de las normas morales. En la actualidad este proceso continúa todavía, por ejemplo, en cuanto que los principios y argumentos morales se separan de los fundamentos del derecho. En general, podemos constatar que en todos los sectores de la vida pública en la sociedad industrial occidental, las justificaciones morales de la praxis se sustituyen por argumentos pragmáticos, que los 'expertos' suministran sobre la base de reglas científico-tecnológicas objetivables" (Apel 1985, p. 352).

En este contexto, Apel se ha referido explícitamente en varios de sus trabajos al proyecto rawlsiano, aunque no siempre ha sido para alabar una empresa que cada vez con mayor notoriedad va sumergiendo el "factum de la razón" en el desencanto (Apel 1988 y 1997b). Esto es, en la imposibilidad de que la misma razón, o mejor, alguna forma específica de racionalidad (tal como la razón dialógica que participa en los discursos argumentativos) pueda proporcionar con validez universal ese basamento ético que requieren las normas jurídicas y morales que son exigibles para las sociedades modernas con democracia liberal.

Lo cierto es que el Rawls que va desde A Theory of Justice hasta "Kantian Constructivism in Moral Theory" (Rawls 1999a y 2001, pp. 303-358), coincidía con Apel (y también con Habermas) en recoger a través de una empresa reconstructiva el legado político-moral kantiano haciendo de la persona autónoma el punto clave y, al mismo tiempo, situando el mundo moral en ese nivel postconvencional en el desarrollo de la conciencia moral que permite a los sujetos juzgar acerca de la justicia desde principios que rebasan los límites del ethos de una comunidad concreta. A juicio de Apel, en este sentido, Theory debería considerarse como un planteamiento complementario al problema de la justicia intercultural, ya que "el fundamento filosófico 'autosuficiente' de los 'principios de la justicia' iba a asegurar la prioridad de lo 'correcto' -y hasta ahora de una moralidad universalmente válida- por encima de lo 'bueno', perteneciente a las distintas 'doctrinas comprehensivas' de la metafísica y la religión, dependientes de la cultura” (Apel 2003, p. 203).

Sin embargo, también es cierto que el "segundo" Rawls -o sea, el de Political Liberalism (1996) - se distancia de ese punto de vista moral universal, renunciando con ello, y dicho hegelianamente, al trabajo del concepto (o al de la razón, que lo mismo da), refugiándose en las condiciones más pragmáticas de lo razonable que elude las exigencias de validez impuestas para todo ser que desea servirse en serio de su capacidad racional y no quedarse instalado simplemente en lo dado, en el "factum de la tradición política" (Habermas 1998c). Con ello parece que las bases de la ética 
son dependientes de la cultura, o más especificamente aun, de una determinada cultura política de origen liberal. He aquí, entonces, que en cuanto persiste la dependencia cultural de la ética, así también subsiste el problema de determinar las condiciones morales y jurídicas de una sociedad multicultural, dilema que todavía no puede evitarse en nuestros días en la mayoría de los estados constitucionales ${ }^{1}$.

A este tenor, el "segundo" Rawls representa, a juicio de Apel, un buen ejemplo de la tendencia pragmática de la filosofía moral actual (Apel 2003, p. 203). En este sentido, el giro más significativo en el Rawls postrero a Theory, Apel lo identifica a partir del ensayo "Justice as Fairness: Political not Metaphysical" de 1985 (Rawls 2001, pp. 388-420), en el que "parece negar, o respectivamente revocar, la pretensión de universalidad de su anterior base para una ética de justicia y equidad, a favor de un recurso neoaristotélico o historicista a la tradición, muy estadounidense, del 'sentido de justicia"” (Apel 2001, p. 230). Este sería el cambio más decisivo que se proyecta con posterioridad en Political Liberalism, lugar en el que, según Apel, Rawls abandona "la exigencia de un fundamento 'filosófico' autosuficiente, y hasta 'moral' de la teoría de la justicia” (Apel 2003, p. 203). En esta medida, Rawls limita la exigencia de su teoría de la justicia, la cual queda estrechada en una propuesta estrictamente política (hipotética) que espera encontrar apoyo por parte de la mayoría de las doctrinas comprehensivas de lo bueno y así poder convertirse en la base de un consenso entrecruzado en el mundo político.

Para Apel, en la medida en que los argumentos rawlsianos representan una renuncia a la posibilidad de un fundamento filosófico de la concepción de la justicia, esto trae consigo un nuevo cuestionamiento sobre la supuesta naturaleza kantiana de su teoría. Pero no solo eso, además, representa un abandono a la posibilidad misma de "un genuino principio de universalización de procedencia kantiana, es decir, a un principio que, en nombre de su propia autoridad moral, también puede dirigirse en contra de aquellos tipos de 'consenso entrecruzado' que de hecho pueden alcanzarse de cara a la constelación actual de perspectivas comprehensivas en el mundo político" (Apel 2003, p. 204). A fin de cuentas, en el caso del "segundo" Rawls solo se trataría de diseñar las condiciones de posibilidad fácticas o que de hecho facilitan el consenso entrecruzado al interior de la cultura política, pero cuyo esfuerzo adolece en último término de cualquier autoridad moral -a no ser la misma tradición liberal-que pueda ser dirigida de forma no convencional contra otros eventuales tipos de consenso entrecruzado.

En este sentido, un recurso al relativismo historicista tipo Rorty no es compatible con una solución a este problema, ya que, como nos dice Apel: "no sólo las diferencias de las existentes tradiciones de ethos dependientes de la cultura han de ser reconocidas y respetadas [...], sino también y al mismo tiempo, la igualdad del derecho a la singularidad de las distintas culturas. Además, incluso el compromiso de la responsabilidad relacionada con la historia (con respecto al medio ambiente, por citar un ejemplo) ha de ser adquirido por todas las comunidades culturales" (Apel 2003, pp. 201-202, también 1988). 
A mi modesto entender, la crítica de Apel a Rawls se puede concretar -tal como procede Habermas- en la idea sobre el uso de la razón pública-política en una democracia constitucional, la cual pretende ofrecer un estatus de objetividad no valorativa reflejada en los límites impuestos por el Derecho -el cual permite o restringe ciertas prácticas como resultado de decisiones no moralmente evaluativas por parte de las diferentes doctrinas comprehensivas de lo bueno. En esta dirección creo que podríamos sostener que Rawls hace un uso pragmático del principio de tolerancia en el uso de la razón pública, al poner entre paréntesis de un modo convencional la deliberación moral (en el ámbito político) ante los casos concretos más problemáticos - por ejemplo, en el caso del aborto (Sandel 1989)-, con el fin de establecer metas públicas razonables (esto es, abiertas a la decisión subjetiva), pero sin atender a la validez racional e intersubjetiva de los resultados deliberativos no políticos, ciertamente también morales, que afectan a cada ámbito de la vida cotidiana de los ciudadanos.

Ciertamente que desde una perspectiva apeliana esto no prejuzga de la necesidad de pactos basados en los hechos que se sostienen en un consenso entrecruzado de doctrinas comprehensivas (metafísicas y/o religiosas), tal como demuestra el caso de los derechos humanos. Tales pactos son necesarios, al menos, como precondiciones del progreso institucional a escala local como global. Sin embargo, esto no sustituye el hecho de que necesitemos a su vez una respuesta postconvencional y postradicional de la filosofía moral que represente los intereses de todos los afectados, actuales y potenciales, que son virtualmente copartícipes del discurso argumentativo. El hecho que tengamos que debatir cualquier materia controvertida por medio de un discurso argumentativo no es, para Apel, una mera "cuestión contingente o incidental, puesto que no existe ninguna alternativa razonable a tal procedimiento, siempre que no deseemos luchar o negociar, sino determinar, por medio de argumentos pertenecientes al ámbito de la razón, quién está en lo cierto sobre la cuestión objeto de debate" (Apel 2001, p. 233). Llegados a este punto, el procedimiento del discurso argumentativo -como algo que pertenece al factum de la razón no contingente, en sentido kantianoes insuperable en filosofía respecto a las controversias morales del mundo vital, ya que constituye la única institución humana capaz de proporcionar una solución posible y razonable a semejantes controversias.

Por este motivo, en la posición apeliana el principio procedimental de consenso de la ética del discurso - que, como hemos afirmado, puede ser considerado como una transformación del principio kantiano de universalización- exige un consenso posible de todas las personas afectadas con atención a los efectos probables de una obediencia universal de las normas que podrían ser propuestas en el discurso práctico. El principio procedimental establece una autoridad moral postconvencional propia y, por ende, puede servir como una idea regulativa, incluso para las condiciones tradicional y multiculturalmente cambiantes bajo las cuales debe alcanzarse un consenso entrecruzado fáctico en el mundo político (Apel 2003, p. 204). En este sentido, la idea apeliana pretende incluir también los eventuales intereses de los participantes virtuales del discurso que deben asumir corresponsablemente las consecuencias derivadas de los acuerdos que son el resultado de tal consenso. Pero para que esto sea posible, 
como hemos dicho antes, es insuficiente la pura comunidad real y, por tanto, es necesario un punto de apoyo no limitado por el ethos concreto y particularista del que dependen los acuerdos fácticos en que se basa el posible consenso entrecruzado. De ahí la importancia de la comunidad trascendental o del a priori de la comunidad de comunicación como referente insoslayable de legitimación de los acuerdos reales llevados a cabo fácticamente.

Llegados a la conclusión de este parágrafo, habría que decir que las valoraciones o los valores específicos de la vida buena que se ponen de manifiesto en las distintas formas socioculturales de vida, podrían o deberían ser reconocidas por medio de formas universalmente válidas de discurso argumentativo. En este sentido, ¿cómo pueden ser reconciliadas sobre el trasfondo histórico de la totalidad de nuestras nociones acerca del bien esa diversidad de formas socioculturales de vida que subsisten en una sociedad multicultural? Esta cuestión se relaciona con la pregunta sobre la fundamentación ética de la tolerancia afirmativa, asunto que pasamos a examinar en el siguiente parágrafo.

\section{La fundamentación ético-discursiva de la tolerancia afirmativa}

Para Apel, la pregunta normativa básica sobre la tolerancia afirmativa en una sociedad multicultural sería la siguiente: “¿Podemos, o incluso debemos suponer que hay una pluralidad (y esto significa: una variedad (diversidad)) de lo bueno tal que estamos comprometidos u obligados, de algún modo, a asignar el mismo respeto a todas las diferentes formas de lo bueno?" (Apel 1997a, p. 202). La dificultad del planteamiento consistiría en que el reconocimiento de una pluralidad o variedad de lo bueno, al parecer, favorecería cierto tipo de relativismo y subjetivismo (algo semejante a una idea de verdad separada de la idea de validez intersubjetiva universal [Apel 1995, pp. 37-145]).

En general, Apel admite que es posible el diálogo entre diversas culturas, así como también que se pueden ofrecer buenas razones para aceptar o rechazar determinadas tradiciones culturales. Además, presupone la necesidad de llegar a consensos entre diversas culturas, al menos como idea regulativa (Maureira y Siurana 1997). Para apoyar su posición, nuestro autor asume como punto de partida el análisis de dos conceptos de lo bueno que podemos encontrar en Kant: por un lado, lo bueno deóntico (mínimos de justicia válidos universalmente, de carácter formal) y, por otro lado, lo bueno relativo (lo que una comunidad concreta considera como lo bueno, de carácter substancial) (Apel 1997a, pp. 202-203).

Tomando esta distinción como referencia, podemos decir que Apel defiende la complementariedad entre una macroética universalista y deontológica de lo justo para todos (o sea, una concepción de lo bueno unitaria y universalmente válida), $\mathrm{y}$, al mismo tiempo, una etno-ética teleológico-evaluativa de lo bueno para cada uno de nosotros o para cada una de las culturas particulares (es decir, lo bueno de una variedad 
socio-cultural) (Siurana 2003, pp. 114-115). Entre ambas, Apel sostiene que es posible respetar una variedad socio-cultural de lo bueno en la medida en que se conceda prioridad a las exigencias del primer marco ético normativo por sobre el segundo; esto es, al marco de lo justo frente a lo bueno substancial. En este sentido, fue Kant quien primero subordinó lo bueno relativo que está al servicio de la felicidad -en el sentido de Aristóteles- a lo bueno deóntico o lo bueno de la justicia que proporciona las bases para que todos puedan alcanzar su felicidad ${ }^{2}$. Ciertamente, esto supone para Apel que "respecto a nuestra actitud apropiada hacia la diversidad de tradiciones socio-culturales de valores o formas de vida, debe ser posible dar una respuesta deontológicamente correcta o justa que [...] está obligada a ser válida para todos" (Apel 1997a, p. 203).

Para Apel, sin embargo, la doble distinción de lo bueno que culmina en el principio kantiano de la moralidad como universalización de derechos y deberes no puede proporcionar la base para apreciar las tradiciones de valor particulares -y junto con ello, la posibilidad de la tolerancia afirmativa-, y esto porque no está conectado con la comprensión de que el principio moral de universalización es solo un instrumento para comprobar máximas que, por su parte, en cada caso concreto presuponen una tradición de valor particular de la eticidad substancial en sentido hegeliano (Apel 1997a, p. 204).

Esta limitación es de crucial importancia, pues la distinción kantiana de lo bueno proporciona la base para la otra distinción metaética muy actual en nuestros días entre la ética deontológica y la ética teleológica, la cual se ha convertido, asu $v e z$, en una base para el modo liberal de tratar con el problema de la tolerancia (es decir, a la neutralidad en el sentido del principio de no intervención frente a las diferentes formas de vida individuales y/o socio-culturales) (Mendus 1989, De Páramo 1993, Sánchez 1995).

Desde esta perspectiva, para nuestro autor lo anterior viene a sugerir "una respuesta complementarista al problema de la unidad o la variedad de lo bueno, es decir, una respuesta que muestra que la tolerancia es ella misma un deber deóntico válido universalmente" (Apel 1997a, p. 204). Esto quiere decir que la tolerancia solo puede legitimar la coexistencia de los individuos diferentes y las diversas formas colectivas que asume lo bueno a través de la idea de lo bueno deóntico que es unitario. De ahí que la versión kantiana del liberalismo y su solución complementarista sea insuficiente todavía para resolver el problema ético consistente en fundamentar la tolerancia afirmativa. Al decir de Apel: "según las presuposiciones de Kant de la solución complementarista, sólo una cosa parece clara: que la tolerancia es exigida, en principio, respecto a las diferentes formas de esforzarse por alcanzar la vida buena, y simultáneamente tiene que ser restringida a priori, es decir, de acuerdo con el criterio

2 Sobre la base arquitectónica kantiana, véase la interesante distinción entre "éticas de mínimos" (de justicia) y "éticas de máximos" (de felicidad), ambas complementarias, diseñada por Adela Cortina (1996a y 2001). 
deóntico de la garantía de derechos iguales para todas las formas individuales y socioculturales afectadas" (Apel 1997a, p. 204) ${ }^{3}$.

A este tenor, nuestro autor cree que la versión complementarista de la tolerancia negativa es incapaz de responder a dos tipos de problemas: primero, si existe una obligación de apoyar a todas las diferentes formas de vida individuales y/o socioculturales en la búsqueda de sus ideales de vida dentro de ciertos límites que aseguren la igualdad de oportunidades para todos; y segundo, si es posible realizar la tolerancia afirmativa, como también sus propias restricciones (y eventualmente, incluso las restricciones de la tolerancia negativa).

Ambas, conjuntamente, plantean la pregunta más amplia de si el problema de la tolerancia solo se reduce a una cuestión política que se resuelve en una asamblea legislativa -al estilo de Rawls (1996)-, o si además representa un problema del que deba hacerse cargo la ética. Como es obvio, frente a esta cuestión amplia, Apel defiende no solo la incumbencia de la ética frente al problema de la tolerancia, sino que además sostiene que es posible obtener una respuesta satisfactoria a través de la ética del discurso entendida como una transformación pragmático-trascendental y hermenéutico-trascendental del kantismo. Pero, desde esta perspectiva, ¿cómo se resuelven, entonces, las dos preguntas anteriores?

Respecto a la primera cuestión, nuestro autor nos dirá que desde la perspectiva de la transformación pragmático-trascendental del principio de justicia de Kant, es decir, el principio de la necesaria universalización de los derechos y deberes en una comunidad ideal ilimitada de comunicación, no es posible ser indiferentes hacia los intereses éticos relevantes expuestos en la vida buena de otras personas, individuos o grupos colectivos. Esta exigencia de reconocimiento se mantiene en cuanto todos los participantes del discurso argumentativo, en tanto afectados actuales o virtuales, han reconocido ya su igual corresponsabilidad por el descubrimiento y posterior resolución de todos los problemas respecto a las posibles pretensiones de validez.

En este sentido, como sabemos, las pretensiones de validez involucran en el discurso práctico a todos los intereses éticamente relevantes de todos los miembros virtuales de la comunidad ideal ilimitada de comunicación, por lo que nadie puede quedar excluido. Así, la corresponsabilidad constituye, a juicio de Apel, un principio ético que difiere -o va más allá- del sentido de la justicia (incluso, cuando el ámbito de obligaciones recíprocas entre las personas se extiende a la relación entre generaciones distintas, como de hecho exigiría una macroética [Apel 2001, p. 235]). Esto nos demuestra que a partir de la transformación pragmático-trascendental del hecho trascendental kantiano de la razón "no sólo hemos reconocido un principio de justicia

3 A mi entender, Rawls representa un buen ejemplo, en la medida en que la tolerancia política se expresa en los términos de los derechos y deberes que protegen la libertad de acuerdo con una razonable concepción política de la justicia, la cual ha de ser aceptada por todos los ciudadanos para la justa regulación de la rivalidad de doctrinas comprehensivas de lo bueno (Rawls 1999b: §§ 3 у 7$)$. 
que puede restringirse a la mera neutralidad respecto a todas las diferentes formas de esforzarse por alcanzar la vida buena, sino que hemos reconocido también nuestra corresponsabilidad por intentar entender las preocupaciones de otros e incluso ayudarles - personas individuales y comunidades particulares-a buscar sus propósitos de vida buena dentro de los límites puestos por la justicia como deber de igual tratamiento (es decir, examen discursivo serio) de todas las preocupaciones referentes a la vida buena" (Apel 1997a, p. 205).

Este planteamiento sugiere que el principio de corresponsabilidad trascendental para cada posible argumentador como copartícipe del discurso es fundamental para la realización de la tolerancia afirmativa, en la medida en que su mismo concepto expresa la exigencia ética relevante de ayudar o apoyar -o de "cuidar" sin paternalismoa las distintas formas de vida sociocultural. Por supuesto, como hemos dicho más arriba, la primordial corresponsabilidad por respetar los interes de todas las otras personas tiene que ser distinguida de las obligaciones o deberes institucionales de ayudar a, o cuidar de, ciertas personas en ciertas ocasiones. En este sentido, "el deber de ayudar a otros, dentro de los límites del respeto de su autonomía y sus derechos iguales, es posible en la medida en que cada miembro sea corresponsable por tomar en cuenta (por lo tanto incluso por descubrir) cada interés de los otros que -por interpelación- podría convertirse en una pretensión de validez a examinar y posiblemente reconsiderar a través del discurso argumentativo" (Apel 1997a, p. 206). Así, queda establecida, entonces, una cierta solidaridad de todos los posibles miembros de una comunidad de argumentación que pretenden resolver las condiciones morales y jurídicas de una sociedad multicultural.

De ahí, por tanto, que la tolerancia afirmativa lleve implícita cierta solidaridad no fundada estratégicamente y que se expresa en el hecho fundamental de pretender entender a otras personas. En efecto, en la medida en que entender (lo cual quiere decir: interpretar las expresiones culturalmente impregnadas) es parte de la razón comunicativa y, por lo tanto, de la solidaridad discursiva con otros, a juicio de Apel, podemos hablar también de una dimensión hermenéutico-trascendental de la transformación pragmático trascendental del kantismo. Se trata, en este nivel, no solamente de aceptar que otros pueden tener visiones diferentes sobre la vida, sino de intentar comprender las motivaciones en que se arraigan dichas visiones, buscar puntos de convergencia y, desde aquí, promocionar la diversidad como necesaria para la auténtica identidad de cada sujeto en el marco de la cultura en la que ha sido socializado, de modo que se produzca un mayor enriquecimiento mutuo en las sociedades multiculturales (Siurana 2003, p. 117). Como nos dice Apel: "uno ha de intentar hermenéuticamente comprender y evaluar las tradiciones de valor de las diferentes comunidades etno-religiosas y las formas de vida, para apreciar tanto como sea posible sus posibles contribuciones al enriquecimiento de la vida cultural humana en general" (Apel 1997a, p. 209).

Lo dicho hasta aquí nos permite entrar ahora en el segundo de los problemas reseñados más arriba, a saber, cómo es posible llevar a cabo la tolerancia afirmativa hacia una variedad de formas socioculturales de vida en competencia y simultáneamente restringirla (y eventualmente restringir la tolerancia negativa). Sobre este 
aspecto, habría que comenzar diciendo que la tolerancia afirmativa no sugiere seguir todas las variedades multiculturales de lo bueno, sino más bien medirlas críticamente, tomando como referencia la idea regulativa de la solidaridad en la comunidad ideal de comunicación, de manera que queden asegurados los iguales derechos para todas las formas de vida y protegidos los derechos individuales contra las pretensiones dogmáticas de comunidades etno-religiosas.

En este sentido, a juicio de Apel, la ética del discurso tendría que ofrecer dos aportaciones a la solución del segundo problema: uno que depende de la fundamentación pragmático-trascendental y otro que se refiere al discurso práctico.

Respecto a la primera aportación, Apel busca dar con una solución alternativa que sea superior al punto de vista pragmático-empírico dominante en la filosofía moral y política de nuestros días y que se encuentra sugerido en Rawls. Esta perspectiva solo ofrecería una solución a los problemas de la sociedad multicultural buscando "un consenso fáctico, en la línea de un denominador común, entre las comunidades-devalor-existentes -o las más importantes- dentro del marco de un Estado constitucional o incluso dentro del marco de la sociedad humana global" (Apel 1997a, p. 207). En Rawls, ambos puntos de vista corresponderían, por un lado, a la tolerancia en la sociedad doméstica -especialmente con Political Liberalism y "The Idea of Public Reason Revisited"-, y por el otro, a la tolerancia en la sociedad de los pueblos -en The Law of Peoples-, cuyo propósito consiste en alcanzar un "consenso entrecruzado" a nivel local y global no basado en las diversas versiones comprehensivas de lo bueno o las tradiciones de valor existentes (Correa-Casanova 2005).

Más allá de la utilidad práctica de este procedimiento, para Apel la ética del discurso no puede fundarse en un principio regulativo semejante, y esto por tres tipos de condiciones complementarias: primero, porque la ética del discurso exige el discurso real entre todas las posibles partes en conflicto, delegando incluso en ellas la búsqueda de soluciones concretas referentes a las normas materiales; segundo, porque siempre permanece una diferencia entre el consentimiento fáctico entre las partes en conflicto y la idea regulativa de un consenso ideal que supone de forma pragmáticotrascendental una comunidad ilimitada de argumentación; y tercero, porque las normas fundamentales de la ética del discurso -que no son negociables en el discurso práctico-, pueden ser muy diferentes no solo desde las normas materiales que resultan del discurso práctico, sino también desde esas normas cuasi, o pseudo-fundamentales que son fácticamente acordadas por todas las comunidades culturales o tradiciones de valor en competencia dentro de una sociedad multicultural (doméstica o incluso global).

A juicio de Apel, especialmente esta última condición pone en evidencia que la idea regulativa éticamente satisfactoria para una sociedad multicultural no puede estar basada en un principio pragmático-empírico. Al contrario de este principio, la ética del discurso mantiene siempre los criterios trascendentales al realizar la tolerancia afirmativa, así como su necesaria restricción (por ejemplo, en base a la idea de los derechos humanos), los cuales son independientes de los acuerdos fácticos entre los grupos existentes, de tal modo de que sea posible transformar progresivamente cualquier situación de injusticia. Referido a las restricciones de la tolerancia afirmativa, 
esto sugiere, en palabras de Apel, que "uno está obligado a no seguir todas las sugerencias de una variedad multicultural de lo bueno, sino que tiene que medirlas críticamente contra los criterios de lo uno bueno que es reconocido como la idea regulativa de la solidaridad (es decir, la justicia e igual corresponsabilidad) en la comunidad ideal de comunicación" (Apel 1997a, p. 209).

Si aplicamos lo dicho al caso de los derechos de las mujeres, por ejemplo, esto vendría a significar para Apel que no se puede aceptar que pertenecer a una comunidad de valor particular es por sí mismo un derecho humano individual (o incluso grupal o colectivo), razón por la cual tenemos que resistirnos a sacrificar los derechos humanos individuales universalmente válidos a favor de las tradiciones de valor particulares. En este punto, por cierto, se podría sostener que Apel coincide con autores como Rawls o Kymlicka, e incluso Walzer, sobre la negativa a violar los derechos individuales en contra de los mandatos de justicia garantizados por el Estado a todos los ciudadanos. Sin embargo, la tolerancia afirmativa resalta otro aspecto éticoevaluativo que no contemplan los autores mencionados, a saber, que asumir una posición hermenéuticamente comprensiva y evaluativa de las tradiciones de valor de las diferentes comunidades "no es sólo un asunto de dar efecto a las leyes positivas del país de uno contra los extranjeros, sino también (y primariamente) un asunto de comprometerse por los estándares críticos de una moralidad universal -uno puede incluso decir, con Kohlberg, comprometerse por los estándares post-convencionales de la moralidad contra los estándares convencionales de una forma tradicional de vida" (Apel 1997a, p. 209).

A este tenor, no obstante, Apel reconoce que existen innumerables casos que son muy difíciles de resolver satisfactoriamente frente a la variedad o diversidad de tradiciones de valor dentro de una sociedad multicultural (a escala doméstica o global). De ahí que según la ética del discurso no sea necesario ni deseable suponer que las soluciones concretas al problema de mediar entre, por un lado, las diferentes pretensiones de tradiciones de valor o formas de vida y, por otro lado, las pretensiones universales de la moralidad post-convencional, deba ser deducida de una vez y para siempre. Por el contrario, los principios de la ética del discurso exigirían a priori que las soluciones concretas han de ser buscadas de forma dinámica a través de los discursos prácticos -aunque, por cierto, sin renunciar a la mediación ético-discursiva-entre los representantes de los Estados constitucionales y los de las diversas comunidades etno-religiosas.

La aportación de la ética del discurso en este aspecto consistirá en la de exigir los discursos reales entre las partes en conflicto de diversas culturas (sea en la sociedad doméstica o en la global). En este sentido, Apel sostiene que es necesario diferenciar, al menos, entre tres tipos ideales de discurso (Apel 1997a, p. 210):

1. El discurso práctico, tal y como es postulado por la ética del discurso. O sea, el discurso hermenéuticamente mediado y la apreciación de tradiciones particulares de valores y los estándares universalmente válidos de moralidad de la comunidad ideal de comunicación, de acuerdo con la idea regulativa de la complementariedad entre la tolerancia afirmativa y sus restricciones necesarias. 
2. El discurso político, donde a través de los imperativos ético-discursivos uno tiene que considerar, en primer lugar, los compromisos viables entre los intereses de las comunidades etno-religiosas existentes, manteniendo abierta la posibilidad del progreso hacia una sociedad multicultural cosmopolita.

3. El discurso jurídico, que tiene que mediar entre la legislación política y un sistema coherente de derecho positivo que, en los modernos Estados constitucionales, ha de ser capaz de conectarse él mismo con un sistema potencialmente cosmopolita de derecho, por ejemplo, de los derechos humanos.

Un aspecto importante de esta triple distinción consiste en que cuando se considera el nivel del discurso jurídico -más que el discurso político- puede ser suficiente como idea regulativa la tolerancia negativa o neutralidad respecto a las peculiaridades de las diferentes tradiciones de valores o formas de vida. Para Apel, esto es así, porque en el discurso jurídico la garantía de los derechos individuales y del igual trato a todas las tradiciones culturales de valor está obligada a tener prioridad sobre el descubrimiento y la apreciación de nuevos valores aceptables.

\section{5. ¿Tolerancia afirmativa o respeto (activo)?}

El resumen de las reflexiones de Apel sobre la tolerancia desde el punto de vista de la ética filosófica revela su valor más importante, a mi juicio, en su objetivo principal, el cual consiste en ofrecer un fundamento ético intersubjetivamente válido para el reconocimiento de las distintas formas de vida sociocultural y, al mismo tiempo, restringir el respeto debido a cada una de ellas. Desde esta perspectiva, la tolerancia afirmativa se convierte en un deber deóntico válido también universalmente en los discursos reales -sobre todo en los discursos prácticos y los políticos y, en menor medida, en los discursos jurídicos-que presupone de forma pragmático-trascendental la corresponsabilidad solidaria de todos los que son copartícipes de la comunidad ideal de comunicación (sea en el ámbito doméstico o en el global).

Lo anterior, sin embargo, no significa que debamos aceptar de forma acrítica la transformación ético-discursiva de la tolerancia. A este tenor, y dejando de lado las críticas al fundamento ético-discursivo o la distinción misma entre dos modelos de tolerancia (Zolo 1997), creo que sería más acertado proponer un cuestionamiento referido a la necesidad complementarista de una tolerancia afirmativa hacia las diferentes tradiciones de vida socio-cultural que se realizan en una sociedad multicultural. En este sentido, nos podríamos preguntar si es necesario mantener el principio de tolerancia afirmativa, o si quizá sería mejor dejarla de lado para asumir otras categorías de mayor rango moral y que se presentan como más acordes con las premisas éticas que Apel considera como imprescindibles para las sociedades multiculturales.

Efectivamente, si la tolerancia afirmativa se resuelve en último término en la exigencia hermenéutico-trascendental de la interpretación cultural y pragmático-trascendental del apoyo o incluso la promoción de la variedad de las diferentes formas de 
vida socioculturales o las tradiciones de valor, entonces uno podría preguntarse qué aporta la tolerancia afirmativa en el marco de los regímenes constitucionales que sea diferente a la protección de ese espacio libre para nuestra singular automanifestación que ya no se encuentre presupuesto -incluso como una exigencia moral- por la tolerancia negativa (la cual, como sostiene Habermas, encuentra sus límites en los fundamentos normativos de una Constitución de la que procede la legitimidad a conformar la propia singularidad cultural [Habermas 2003, p. 12]).

A la luz de este aspecto estoy de acuerdo con Tomás y Valiente sobre el hecho fundamental de que en las actuales condiciones de las democracias modernas, la tolerancia tiene que cambiar de significado, más radicalmente aun, tiene que dejar paso a la categoría moral del "igual respeto" (Tomás y Valiente 1996, pp. 223-250). Por este motivo, opino que una de las más destacadas intérpretes del pensamiento apeliano entre nosotros, como Cortina, acierta mejor que Apel al preferir hablar de respeto (activo) en lugar de tolerancia afirmativa ${ }^{4}$. A partir de lo que denomina como las exigencias de una ética intercultural para afrontar los problemas de una sociedad multicultural, nuestra autora se niega a realizar esa transformación pragmático-trascendental y hermenéutico-trascendental apeliana del principio de tolerancia-innecesaria, a su entender-, y en coherencia con sus postulados éticos sostiene que el valor auténticamente positivo es, más que la tolerancia, el respeto (activo).

A juicio de Cortina, la problemática multicultural se conecta con la existencia de los Estados poliétnicos, y no tanto con los Estados multinacionales, o con la existencia en una misma sociedad de grupos tradicionalmente desfavorecidos (por ejemplo, las mujeres, los homosexuales, etc). Bien entendidos, los Estados poliétnicos son aquellos en que conviven etnias diversas, que poseen no solo un sentido racial, sino también distintas cosmovisiones que piden respeto y apoyo para mantener y transmitir su forma de vida, lo cual requiere en ocasiones reconocer derechos colectivos, y no solo individuales, para mantener su cultura y su religión.

En este contexto, Cortina entiende la noción de cultura -en sentido fuerte-, como un conjunto de pautas de pensamiento y de conducta que dirigen y organizan las actividades y producciones materiales y mentales de un pueblo, y que pueden diferenciarlo de los demás. En cuanto que toda cultura expresa una cosmovisión, esto quiere decir que contiene un modo específico de concebir el sentido de la vida y de la muerte, así como también una justificación de la existencia de diferentes normas y valores morales. Por eso las culturas poseen una aspiración intergeneracional, o sea, ponen de manifiesto el deseo de sus propios miembros adultos por prolongar dicha cultura en sus futuros descendientes. Este deseo expresa en una sociedad multicultural una cuestión

4 Habría que advertir de todos modos que nuestra autora había postulado en principio la distinción entre "tolerancia pasiva" y "tolerancia activa", significando con ello dos diferentes actitudes: por parte de la primera, la simple actitud de no inmiscuirse en los asuntos de los demás, y, por la segunda, el respeto de los proyectos ajenos (Cortina 1994, 41-42). Luego, nuestra autora desarrolla el fundamento de la tolerancia activa (o respeto) en las exigencias de una ética mínima o ética civil válida universalmente (1996b). 
fundamental de justicia para con la identidad de las personas. De aquí surgiría una serie de preguntas, como por ejemplo, si todas las culturas son igualmente respetables; o si para proteger una cultura basta con que un grupo de personas se identifiquen con ella o, por el contrario, si es preciso que además aporte algo valioso a la sociedad en su conjunto, con lo que se plantea la cuestión de si todo se reduce al reconocimiento de derechos personales, o bien, de riqueza cultural.

El problema estrictamente multicultural, entonces, hace referencia al conjunto de fenómenos que se derivan de la difícil convivencia en un mismo espacio social de personas que se identifican con diversos bagajes culturales. Tales problemas no proceden tanto del simple hecho de que existan diversas culturas, sino del hecho de que exista una cultura dominante que abre paso en una misma sociedad a una distinción entre una "cultura de primera" y "culturas de segunda", lo cual suscita obviamente sentimientos de injusticia y desinterés por las tareas colectivas, pues resulta muy difícil sentirse ciudadano de un mismo Estado o comunidad política que sitúa la cultura propia en un segundo lugar (Cortina 1998, p. 188). Dado este hecho, ¿cómo saberse y sentirse ciudadano igual cuando la propia cultura es preterida? ¿Cómo aceptar las normas políticas, e incluso el compromiso con la vida colectiva, en una comunidad política cuyo contexto cultural resulta extraño?

Para responder a estas cuestiones, y en la línea de los Estados poliétnicos, Cortina propone trabajar a favor de una ética intercultural, la cual "invita a un diálogo entre diversas culturas, de forma que respeten sus diferencias y vayan dilucidando conjuntamente qué consideran irrenunciable para construir desde todas ellas una convivencia más justa y feliz" (Cortina 1998, p. 183). Con ello, nuestra autora afirma que los problemas multiculturales no son solo de justicia, sino también de riqueza huma$n a$, lo cual significa que no se debe tener a todas las culturas por igualmente dignas a priori, así como tampoco como carentes de todo valor, sino que cada una de ellas ha de mostrar hasta qué punto es humanamente valiosa para el conjunto de la sociedad. El respeto debido a cada cultura, entonces, no supone un principio incondicional aplicable a todas las culturas indiscriminadamente. Es necesario tratar de comprender la cultura a la que pertenecen las otras personas, lo cual posibilita también la autocomprensión de la cultura propia.

De este modo, a juicio de Cortina, una ética intercultural no se contenta con asimilar las culturas relegadas a la dominante, ni siquiera con la mera coexistencia de las culturas, sino que fomenta cuatro tareas fundamentales que serían las siguientes (Cortina 1998, pp. 186-187):

1. Permitir, en un mismo Estado, la adhesión a identidades culturales diversas.

2. Rechazar las discriminaciones por motivo de posición social, edad, sexo o raza, aunque sean defendidas por alguna cultura particular.

3. Practicar el respeto activo hacia la identidad elegida de las personas.

4. Comprender las otras culturas, como elemento indispensable para comprender la propia. 
La ética intercultural, por tanto, defiende la búsqueda cooperativa de la verdad y la justicia. La norma justa es la aceptada por todos los afectados tras un diálogo en condiciones de simetría, un diálogo que exige la comprensión de los diversos bagajes culturales de los interlocutores comprometidos. Al Estado corresponde en este sentido asegurar "un espacio público autónomo en el que entablen un diálogo abierto los diferentes grupos culturales y las diversas asociaciones de distinto cuño" (Cortina 1998, p. 216).

A este tenor, como hemos anticipado, no toda diferencia cultural es igualmente respetable. Hay algunas que aunque no estemos de acuerdo con ellas, al menos reflejan una riqueza humana que desde un punto de vista moral es importante para las personas que se identifican con ellas; en cambio, existen otras que no lo son, como aquellas que consideramos simplemente inmorales y denunciables, tales como la discriminación por razón de sexo, raza o religión. Por este motivo, más que la tolerancia, Cortina defiende lo que denomina como el respeto activo, el cual consiste "no sólo en soportar estoicamente que otros piensen de forma distinta, tengan ideales de vida feliz diferentes a los míos [lo que sería la tolerancia negativa], sino en el interés positivo por comprender sus proyectos, por ayudarles a llevarlos adelante, siempre que representen un punto de vista moral respetable" (Cortina 1998, p. 240).

El respeto activo, por tanto, posee dos dimensiones complementarias: por un lado, un aprecio positivo de la diferencia, y, por el otro lado, un interés activo, incluso podríamos decir promocional, porque siga existiendo como tal diferencia. Ambas dimensiones, conjuntamente, vendrían a expresar en una sociedad multicultural una forma de convivencia entre las variadas formas de vida etno-cultural que va más allá de la tolerancia negativa, para connvertirse en una auténtica construcción compartida que promueve la responsabilidad solidaridad que nace del respecto (Cortina 1995a).

\section{Referencias bibliográficas}

Apel, Karl-Otto (1985), "El a priori de la comunidad de comunicación y los fundamentos de la ética. El problema de una fundamentación racional de la ética en la era de la ciencia", en La transformación de la filosofía [1973], 2 vols. Madrid: Taurus; II, pp. 341-413.

(1986), Estudios éticos. Barcelona: Alfa.

(1988), Diskurs und Verantwortung. Frankfurt a. M.: Suhrkamp.

(1994), "Las aspiraciones del comunitarismo anglo-americano desde el punto de vista de la ética discursiva" [1993], en D. Blanco, J. Pérez y L. Sáez (eds.): Discurso y realidad. En debate con K.-O. Apel. Madrid: Trotta; pp. 2425.

(1995), Teoría de la verdad y ética del discurso. Barcelona: Paidós.

(1997a), "Plurality of the Good? The Problem of Affirmative Tolerance in a Multicultural Society from an Ethical Point of View", Ratio Juris, 10, n 2. pp. 199-212. 
(1997b), "Das Problem der Gerechtigkeit in einer multikulturellen Gesellschaft", en R. Fornet-Betauncourt, ed., Armut im Spannungsfeld zwischen Globalisierung und dem Recht auf eigene Kultur. Aachen: AugustinusBuchhandlung.

(2001), "Una macroética planetaria para la humanidad: necesidad, dificultad aparente y posibilidad eventual", en E. Deutsch, ed., Cultura y modernidad [1991]. Barcelona: Kairós; pp. 219-236.

(2003), "Globalización y necesidad de una ética universal. El problema a la luz de una concepción pragmático-trascendental y procedimental de la ética discursiva", en A. Cortina y D. García-Marzá, eds., Razón pública y éticas aplicadas. Madrid: Tecnos; pp. 191-218.

Blanco, Domingo / Pérez, José A. y Sáez, Luis, eds. (1994), Discurso y realidad. En debate con K.-O. Apel. Madrid: Trotta.

Cortina, Adela (1989), "La ética discursiva”, en V. Camps, ed., Historia de la ética (3 vols.). Barcelona: Crítica; III, pp. 533-576.

(1992), "Ética comunicativa", en V. Camps, dir., Concepciones de la ética. Madrid: Trotta; pp. 177-199.

(1994), Ética de la empresa. Madrid: Trotta.

(1995a), Razón comunicativa y responsabilidad solidaria [1985].

Salamanca: Sígueme.

(1995b), Ética sin moral [1990]. Madrid: Tecnos.

(1995c), "Karl-Otto Apel. Verdad y responsabilidad", en K.-O. Apel:

Teoría de la verdad y ética del discurso. Barcelona: Paidós; pp. 9-33.

(1996a), Ética mínima [1986]. Madrid: Tecnos.

(1996b), "Ética civil y cultura de la tolerancia", en F. Fuente, coord., Cultura de la tolerancia. Madrid: BAC; pp. 13-27.

(1998), Ciudadanos del mundo [1997]. Madrid: Alianza.

(2001), Alianza y Contrato. Madrid: Trotta.

Correa-Casanova, Mauricio (2005), La tolerancia liberal. John Rawls en diálogo con sus críticos. Tesis Doctoral, Universitat de València (España); 345 págs.

Crisp, Roger (1992), “Communitarianism and Toleration”, en J. Horton y P. Nicholson, eds., Toleration: Philosophy and Practice. Avebury; pp. 108-125.

De Páramo, Juan R. (1993), Tolerancia y liberalismo. Madrid: CEC.

Dussel, Enrique (1998), Ética de la liberación. Madrid: Trotta.

Habermas, Jürgen (1998a), Conciencia moral y acción comunicativa [1983]. Barcelona: Península.

(1998b), Escritos sobre moralidad y eticidad. Barcelona: Paidós.

(1998c), "Razonable versus verdadero, o la moral de las concepciones del mundo", en J. Habermas y J. Rawls, Debate sobre el liberalismo politico. Barcelona: Paidós; pp. 147-181. 
(2000), Aclaraciones a la ética del discurso [1991]. Madrid: Trotta. (2003), "De la tolerancia religiosa a los derechos culturales", Claves de razón práctica. 129: 4-12.

Maureira, Max y Siurana, Juan C. (1997), “¿Es posible llegar a consensos en sociedades multiculturales? Una aproximación desde la ética del discurso de K.-O. Apel", Dilema. 1: 32-37.

Mendus, Susan (1989), Toleration and the Limits of Liberalism. Hong Kong: Macmillan.

Muguerza, Javier (1991), Desde la perplejidad. Madrid: FCE.

Papacchini, Angelo (1996), "Comunitarismo, liberalismo y derechos humanos”, en F. Cortés y A. Monsalve, eds., Liberalismo y comunitarismo. Valencia: Alfons El Magnànim; pp. 231-261.

Rawls, John (1996), Political Liberalism [1993]. New York: Columbia University Press.

(1999a), A Theory of Justice [1971]. Oxford: Oxford University Press.

(1999b), The Law of Peoples and "The Idea of Public Reason Revisited". Cambridge, Mass., and London: Harvard University Press.

(2001), Collected Papers, ed. by S. Fremann, Cambridge Mass., and London: Harvard University Press.

Sánchez, María O. (1995), "La pretensión de universalidad y la tensión de la tolerancia”, en Derechos y Libertades. II. 5, pp. 451-459.

Sandel, Michael (1989), "Moral Argument and Liberal Toleration: Abortion and Homosexuality", California Law Review. 77, n² 2, pp. 511-538.

Siurana, Juan C. (2003), Una brújula para la vida moral. La idea de sujeto en la ética del discurso de Karl-Otto Apel. Granada: Comares.

Taylor, Charles (1999), Las fuentes del yo. La construcción de la identidad moderna [1989]. Barcelona: Paidós.

Thiebaut, Carlos (1991), “LLa emancipación desvanecida?”, en Ibíd., ed., La herencia ética de la ilustración. Barcelona: Crítica.

Tomás y Valiente, Francisco (1996), A orillas del Estado. Madrid: Taurus.

Walzer, Michael (1996), Moralidad en el ámbito local e internacional [1993]. Madrid: Alianza Universidad.

Zolo, Danilo (1997), "Positive Toleration: An Ethical Oxymoron", Ratio Juris. 10, $\mathrm{n}^{\circ}$ 2, pp. 247-251. 